\title{
Coming to terms with the nonmedical use of prescription medications
}

\author{
Carol J Boyd ${ }^{* 1}$ and Sean E McCabe ${ }^{2}$
}

Address: ${ }^{1}$ Institute for Research on Women and Gender, Substance Abuse Research Center and Nursing and Women's Studies, the University of Michigan, 204 S. State Street, Ann Arbor, Michigan 48109-1290, USA and 2 Substance Abuse Research Center and Institute for Research on Women and Gender, the University of Michigan, 2025 Traverwood Drive, Suite C, Ann Arbor, Michigan 48105-2194, USA

Email: Carol J Boyd* - caroboyd@umich.edu; Sean E McCabe - plius@umich.edu

* Corresponding author

Published: 18 November 2008

Substance Abuse Treatment, Prevention, and Policy 2008, 3:22 doi:10.1186/1747-597X-3-22

This article is available from: http://www.substanceabusepolicy.com/content/3/1/22

(C) 2008 Boyd and McCabe; licensee BioMed Central Ltd.

This is an Open Access article distributed under the terms of the Creative Commons Attribution License (http://creativecommons.org/licenses/by/2.0), which permits unrestricted use, distribution, and reproduction in any medium, provided the original work is properly cited.
Received: 2 December 2007

Accepted: 18 November 2008

\begin{abstract}
In this commentary we highlight limitations with the way nonmedical use of prescription medications has been measured in U.S. national studies. We also offer an alternative way of conceptualizing the nonmedical use of prescription medications for future study.
\end{abstract}

The term nonmedical use of prescription medications is often used by researchers to describe the misuse of controlled medications by people who misuse someone else's prescription medication(s) or patients who misuse their own prescription medications (without a physician's knowledge). Nonmedical users may abuse their own medicines via non-oral routes to get high (e.g., snorting) while other nonmedical users may be given pills (for instance, from a family member) to self-treat a medical condition. Those with their own prescriptions may divert their medications to nonmedical users, while some nonmedical users may engage in doctor shopping in order to obtain a "legal" prescription. Thus, the term nonmedical use of prescription medications has come to characterize a heterogeneous group of motivations and related behaviors.

Despite the recent attention devoted to this form of drug abuse, relatively little is known about the different behaviors associated with the nonmedical use of prescription medications. Neither misuse of one's own medications nor motivations to engage in nonmedical use are adequately assessed in many of the existing epidemiologic studies that focus on substance abuse, including the National Survey on Drug Use and Health (NSDUH) [1],
Monitoring the Future (MTF) [2], and the National Epidemiologic Survey on Alcohol and Related Conditions (NESARC) [3]. While these large studies have contributed to our initial understanding of nonmedical use, it is equally true that they have failed to advance our understanding of the diversity of behaviors associated with the nonmedical use of prescription medications.

Each of the three national studies relies on somewhat different survey questions to assess the nonmedical use of prescription medications - and each has limitations. Monitoring the Future uses the most straightforward question, stipulating that the drug was taken without a doctor's order, although whether respondents are using their own prescription medications or using diverted medications is not determinable. The NSDUH and the NESARC both use one complex question, stipulating that the drug was not prescribed and then each adding, "was taken for the experience or feeling it caused" (NSDUH) or "to feel more alert, to relax or quiet nerves, to feel better, to enjoy themselves, or to get high or just to see how they would work" (NESARC). The NESARC question also stipulates an increase in amount, frequency, and/or longer duration than prescribed. A complex question means that respondents may answer affirmatively to 
the question but only meet one of the stipulated conditions, making it impossible for researchers to determine exactly which behaviors were endorsed.

Fifteen years ago, Hubbard and colleagues [4] critiqued the way in which "nonmedical use of prescription drugs" was often measured. In their paper, they noted that the NSDUH question used to measure nonmedical use was problematic because respondents were expected to recall multiple sets of information in one question. In the current NSDUH, respondents must decide: a) whether they used a controlled drug without a prescription, or b) whether they used a controlled medication for the experience or feeling it caused, or c) whether they used the controlled medication for some other reason. The NESARC question builds on the NSDUH but then adds even more information to the question. That is, respondents must decide if the controlled medication was: a) taken in greater amounts, or b) more often, or c) longer than prescribed.

There are other problems with the questions about nonmedical use in the national surveys. In one nonmedical use question, the NSDUH combines illicitly produced or "street" versions of drugs with controlled prescription medications. For instance, prescription stimulants such as methamphetamine, Desoxyn ${ }^{\circledast}$, "uppers," "speed," Ritalin ${ }^{\circledast}$ or methylphenidate are all combined within one question. Thus, researchers using the NSDUH stimulant data are forced to use the term "prescription-type" medications when writing about the nonmedical use of stimulant medications. Monitoring the Future and the NESARC have similar problems. In the MTF, the same question asks about "street" amphetamines (e.g., crystal methamphetamine) and prescription medications (e.g. Ritalin ${ }^{\circledast}$ ), although some versions of the MTF specifically ask about individual prescription amphetamines. This forces researchers using the MTF data to use the term "prescription-type" medications when providing prevalence estimates for nonmedical use of amphetamines because street amphetamines are included in the question. The NESARC (Wave 2) has a somewhat different problem. It combines opioid analgesics with Cox-2 inhibitors in a single question about the nonmedical use of prescription pain medications. Thus, a respondent may be categorized as a nonmedical user of prescription pain medications BUT may never have used a prescription opioid (either medically or nonmedically). A Cox-2 inhibitor has no abuse potential and is not controlled (scheduled) medication, while all prescription opioid medications have abuse liability and are controlled. In the NESARC (Wave 2), these medications are "lumped" together into one question.

Given the limitations with the nonmedical questions in the national studies, it is virtually impossible to verify subtypes of nonmedical users from these studies, subtypes that have only been described in smaller, exploratory studies [5-8]. In particular, the national studies make it

Table I: Subtypes of the nonmedical use of controlled drug classes

Person does not possess a legal prescription

MOTIVATED BY:

- Desire to get high; create an altered state or experimentation.

RELATED BEHAVIORS:

- Use in "recreational" settings

- Use for reasons other than self-treatment

- Use of scheduled medication with alcohol or other

drugs simultaneously (co-ingestion)

- May use alternate route of administration

(IV, snorting)
Type I:

A problem behavior that is motivated by the desire to experiment, to get high, or to create an altered state with someone else's medication.

\section{MOTIVATED BY:}

- Desire to alleviate symptoms of an actual or perceived health condition; uses medication for its pharmacological purpose (e.g., uses sleeping medication for insomnia) but does NOT involve mixing with alcohol or other drugs or nontherapeutic routes of administration.

RELATED BEHAVIORS:

- May include an increase in the recommended

frequency, dose, or duration
Person does possess a legal prescription

Type 3:

A problem behavior that is motivated by the desire to experiment, to get high, or to create an altered state with one's own medication. 
very difficult to determine whether the nonmedical user was: using his own controlled medication; using someone else's diverted medication; only using a controlled medication (and not a street drug), or using a controlled medication for the experience it caused or for some other reason.

The measurement limitations related to the "nonmedical use of prescription medications" obscures the complexity of this behavior and its related motives. It is for this reason that we propose that future researchers craft questions that disaggregate nonmedical use from motive and possession (see Table 1), thereby producing data that could better help researchers study the health consequences of the nonmedical use of controlled medications and assist prevention and treatment experts to craft more targeted messages.

\section{Competing interests}

The authors declare that they have no competing interests.

\section{Authors' contributions}

CJB and SEM conceived of the editorial, debated and worked through the conceptualization, and drafted the manuscript together. Both authors read and approved the final manuscript.

\section{Acknowledgements}

The development of this commentary was supported by research grants DA018239, DA018272, and DA020899 from the National Institute on Drug Abuse, National Institutes of Health. The content is solely the responsibility of the authors and does not necessarily represent the official views of the National Institute on Drug Abuse or the National Institutes of Health.

\section{References}

I. Office of Applied Studies: Results from the National Survey of Drug Use and Health, 2005. Rockville, MD: Substance Abuse and Mental Health Services Administration; 2006.

2. Johnston LD, O'Malley PM, Bachman JG, et al.: Monitoring the Future national results on adolescent drug use: Overview of key findings, 2006 (NIH Publication No. 07-6202). Bethesda, MD: National Institute on Drug Abuse; 2007.

3. National Institute on Alcohol Abuse and Alcoholism: National Epidemiologic Survey on Alcohol and Related Conditions Wave I and Wave 2. [http://www.nesarc.niaaa.nih.gov/].

4. Hubbard HL, Pantula J, Lessler JT: Effects of decomposition of complex concepts. In Survey Measurement of Drug Use: Methodological Studies. DHHS Pub. No. (ADM) 92-1929 Edited by: Turner CF, Lessler JT, Gfoerer JC. Washington, D.C.: Government Printing Office; 1992.

5. Boyd CJ, McCabe SE, Cranford JA, Young A: Adolescents' motivations to abuse prescription medications. Pediatrics 2006, I I 8:2472-2480.

6. Boyd CJ, McCabe SE, Teter CJ: Medical and nonmedical use of prescription pain medication by youth in a Detroit-area public school district. Drug Alcohol Depend 2006, 81:37-45.

7. McCabe SE, Cranford JA, Boyd Cl: Motives, diversion and routes of administration associated with nonmedical use of prescription opioids. Addict Behav 2007, 32:562-575.

8. McCabe SE: Screening for drug abuse among medical and nonmedical users of prescription drugs in a probability sample of college students. Arch Pediatr Adolesc Med 2008, 162:225-231.
Publish with Biomed Central and every scientist can read your work free of charge

"BioMed Central will be the most significant development for disseminating the results of biomedical research in our lifetime. "

Sir Paul Nurse, Cancer Research UK

Your research papers will be:

- available free of charge to the entire biomedical community

- peer reviewed and published immediately upon acceptance

- cited in PubMed and archived on PubMed Central

- yours - you keep the copyright
BioMedcentral 